\title{
Unexpected Intraoperative Resecting of Common Trunk of Pulmonary Vein Resulted in an Incidental Pneumonectomy from Left Upper Lobectomy
}

\author{
Takanori Ayabe*, Masaki Tomita, Naohiro Nose, Eiichi Chosa, Kazuhiro Higuchi, \\ Kunihide Nakamura \\ Division of Thoracic and Breast Surgery, Department of Surgery, Faculty of Medicine, University of Miyazaki, \\ Miyazaki, Japan \\ Email: "tayabe@med.miyazaki-u.ac.jp
}

Received 5 August 2016; accepted 27 August 2016; published 30 August 2016

Copyright (C) 2016 by authors and Scientific Research Publishing Inc.

This work is licensed under the Creative Commons Attribution International License (CC BY). http://creativecommons.org/licenses/by/4.0/

(c) (i) Open Access

\section{Abstract}

There is a wide range of anatomical variations in the pulmonary vessels. Some of these variations may cause surgical morbidity during general thoracic surgery. We intended to perform a left upper lobectomy for a 73-year-old male with suspected left lung cancer (lt.U, $S^{3}, 20 \times 20 \mathrm{~mm}, \mathrm{P0}$, E0, D0, PM0, N0, T1anOM0, c-stage IA). Preoperatively, we did not recognize the existence of the common trunk of the left pulmonary vein. After the open thoracotomy, due to a severe intrathoracic adhesion, we omitted releasing the adhesion of the lower lobe. We did not exactly confirm the location of the inferior pulmonary vein (IPV). After cutting the interlobular pulmonary arterial branchies, we resected the superior pulmonary vein (SPV) using auto sutures. After division of the lung parenchyma and incomplete fissures using auto sutures, we intended to resect the upper bronchus. However, we could not find an IPV at the normal IPV site. A thin IPV was found to be returned to the peripheral site of the resected SPV. The SPV and IPV formed a common trunk at the normal site of the SPV. Although we considered reconstructing the resected common trunk, we finally made a decision of performing an incidental pneumonectomy in order to prevent any postoperative complications on the reconstruction of the IPV such as thrombus occlusion at the anastomosis site and venous return congestion. Retrospectively, we confirmed the preoperative images of the computed tomographic scanning, which showed a narrow IPV that returned to the peripheral site of the SPV. It is important to confirm both accurate locations of the SPV and IPV when performing a lobectomy.

${ }^{*}$ Corresponding author.

How to cite this paper: Ayabe, T., Tomita, M., Nose, N., Chosa, E., Higuchi, K. and Nakamura, K. (2016) Unexpected Intraoperative Resecting of Common Trunk of Pulmonary Vein Resulted in an Incidental Pneumonectomy from Left Upper Lobectomy. Open Journal of Thoracic Surgery, 6, 18-24. http://dx.doi.org/10.4236/ojts.2016.63004 


\section{Keywords}

\section{Incidental Pneumonectomy, Common Trunk, Lobectomy, Unexpected, Lung Cancer}

\section{Introduction}

There is a large variety of aberrations in the morphology of the pulmonary vessels.

Especially, the anatomical abnormality of the pulmonary vein may have a serious impact on complications that may arise during a pulmonary lobectomy.

We intended to perform an upper lobectomy for lung cancer; however, because of the severe intrathoracic adhesion, it became a problem to release the entire lower lobe and to confirm the exact location of the inferior pulmonary vein (IPV). After resecting of the superior pulmonary vein (SPV), we found the absence of the IPV. The SPV and IPV formed a common trunk inside the upper lobe, a situation that resulted in the unexpected intraoperative cutting of the common trunk.

Because of a poor preoperative assessment on the locations of the SPV and IPV, we could not recognize its abnormality based on the three-dimensional relationship of the pulmonary vessels and bronchus. Unexpectedly, we had cut the common trunk of the pulmonary vein when performing the upper lobectomy. We report the importance of preoperative detailed confirmation, that is, the three-dimensional anatomical location, its relationship, and exact intraoperative navigation.

\section{Case Report}

In 2011, a 73-year-old male patient was suspected to have left lung cancer (lt.U, $\mathrm{S}^{3}, 20 \times 20 \mathrm{~mm}$, P0, E0, D0, PM0, N0, T1aN0M0, c-stage IA). A computed-tomographic scanning of the chest showed a round grand-glass opacity lesion in the left upper lobe (Figure 1). Eight years ago, the patient had a directional coronary atherectomy due to an old myocardial infarction with hyperlipidemia and hypertension. A left upper lobectomy was scheduled by open thoracotomy.

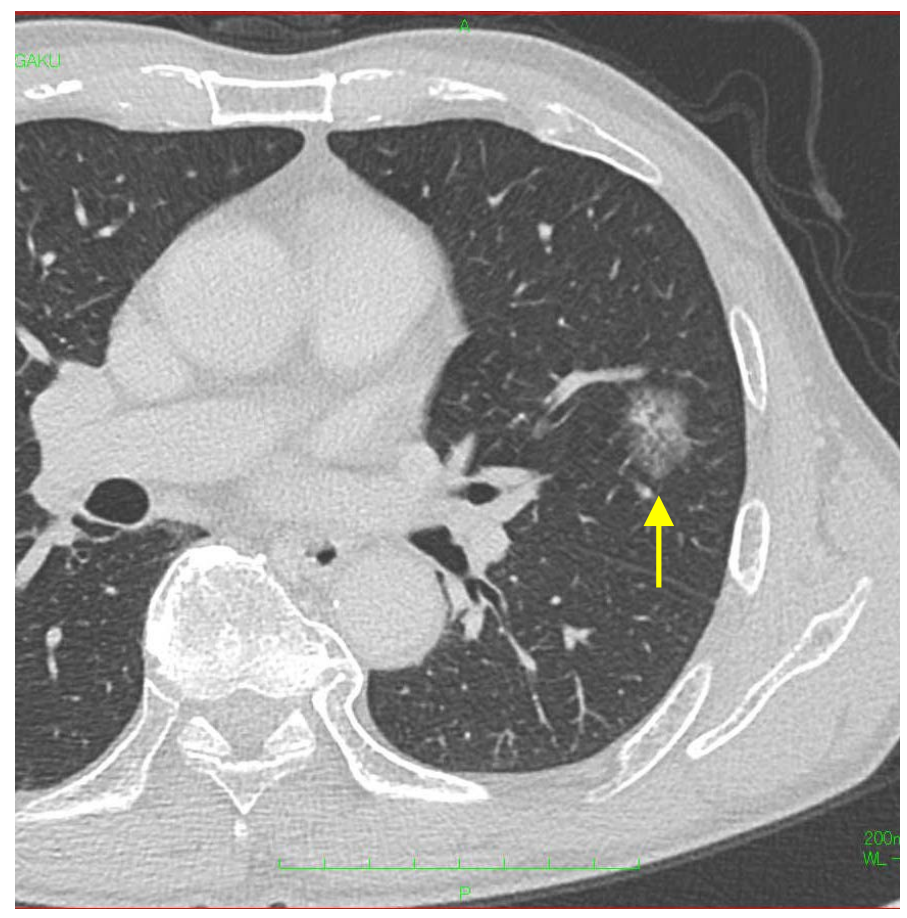

Figure 1. A computed-tomographic scanning showing the grand-glass opacity lesion in the left upper lobe (yellow arrow). 
After the thoracotomy at the $5^{\text {th }}$ intercostal space, the intrapleural space severely adhered to the whole intrathorax. We did not peel off the whole lesion of the lower lobe and did not confirm the exact location of the IPV because we prevented an excessive amount of bleeding and air leaks due to lung injuries of the lower lobe.

The SPV was exposed at the normal site. The interlobular arterial branches were buried with a moderate fibrotic adhesion. After division of the lung parenchyma and incomplete fissures with auto sutures, the interlobular pulmonary arterial branches $\left(\mathrm{A}^{5}, \mathrm{~A}^{4}, \mathrm{~A}^{1+2 \mathrm{c}}, \mathrm{A}^{1+2 \mathrm{a}}, \mathrm{A}^{1+2 \mathrm{~b}}\right.$, and $\left.\mathrm{A}^{3}\right)$ were cut after ligation with $2-0$ silk. The SPV was cut with auto sutures. At the time of exposure of the upper bronchus, we found the absence of the IPV at the normal location. We explored the intralobular peripheral venous tree of the resected SPV. A thin IPV was found at the ventral lower bronchus, which continued inside the lower lobe. The pulmonary venous anomaly formed a common trunk at the normal position of the SPV.

The thin IPV returned to the SPV like a $\mathrm{V}^{45}$ venous branch, which could not be intraoperatively recognized as a common trunk. Retrospectively, we had recognized the SPV as the $\mathrm{V}^{123}$ and $\mathrm{V}^{45}$ vein, however, because the region of the $\mathrm{V}^{45}$ branch had been a so-called thin IPV, we had resected the common trunk as an SPV.

Although we considered reconstructing the resected common trunk and IPV, however, it was rejected in order to prevent postoperative complications, such as pulmonary venous occlusion, congestion due to thrombus, and the pulmonary edema due to the anastomotic stenosis. We altered the scheduled upper lobectomy to perform a pneumonectomy with dissection of the mediastinal lymph nodes.

Intraoperatively, we explained to the patient's family the unexpected adverse event and the conversion of the scheduled operation, that is, performing an incidental pneumonectomy. We obtained informed consent from the patient's family as they understood our explanation and intraoperative decision. After the pneumonectomy, the patient's postoperative course was good. The postoperative pathology revealed adenocarcinoma with a mixed subtype, pT1aN0M0, p-stage IA.

During the follow up of 5 years and six months, the patient was healthy with good quality of life. There was no distant metastasis and local recurrences. At postoperative 5 years, the postoperative pulmonary function test showed a restrictive pattern, that is, vital capacity (VC) (1.32 L), \% VC (48.5\%), forced expiratory volume in 1 second $\left(\mathrm{FEV}_{1}\right)(1.25 \mathrm{~L})$, and \% $\mathrm{FEV}_{1}(98.4 \%)$, although the preoperative values were VC (2.3 L), \% VC (85.3\%), $\mathrm{FEV}_{1}(2.4 \mathrm{~L})$, and $\% \mathrm{FEV}_{1}(78.2 \%)$. The informed consent was obtained from the patient to report this case.

\section{Discussion}

To perform a safe surgery for lung cancer, a preoperative evaluation on the staging, general anesthesia tolerance, preoperative risk, and postoperative outcome has become very important in surgical clinical skills. Preoperatively, in the case of a poor confirming of the anatomical location and relationship of vessels and bronchus, a situation occurs that might produce adverse events such as an unexpected cutting of important vessels and bronchus.

Under the worse condition, such as severe intrathoracic adhesion, in order to avoid pulmonary bleeding and injuries of the emphysematous lung, we omitted the releasing of the entire pleural adhesion. Preoperatively, we did not recognize the existence of a common trunk. We accidentally resected the common trunk using auto sutures. Retrospectively, the common trunk was poorly enhanced by preoperative CT scanning. The IPV was returned to the resected SPV at the peripheral site. The resected specimen revealed that the SPV and IPV formed a common trunk inside the upper pulmonary lobe. We were confused as to whether we should reconstruct the IPV or perform an incidental pneumonectomy. We decided to perform the incidental pneumonectomy in order to minimize the postoperative complications such as postoperative venous occlusion and congestion of the lower lobe. Retrospectively, the images of the computed tomographic scanning (Figures 2-4) were checked, which showed a narrow IPV that returned to the peripheral site of the SPV; the common trunk was weakly enhanced. It is important to confirm the locations of the SPV and IPV before the lobectomy. Figure 5 shows the resected common trunk, and we should have resected the SPV at the peripheral site without cutting of the IPV, which was grasped with forceps. Based on the experience of this rare and unusual case of the unexpected cutting of the common trunk of the pulmonary vein during the left upper lobectomy, we learned the importance of the preoperative assessment of the exact anatomical location of the pulmonary veins by confirmation with three-dimensional computed tomographic scanning.

We found six literature reports regarding the common trunk of the pulmonary vein, 5 cases were about in upper lobe, and 2 were about the lower lobe. Table 1 shows a summary of the seven cases, each of them are described in detail as follows. 


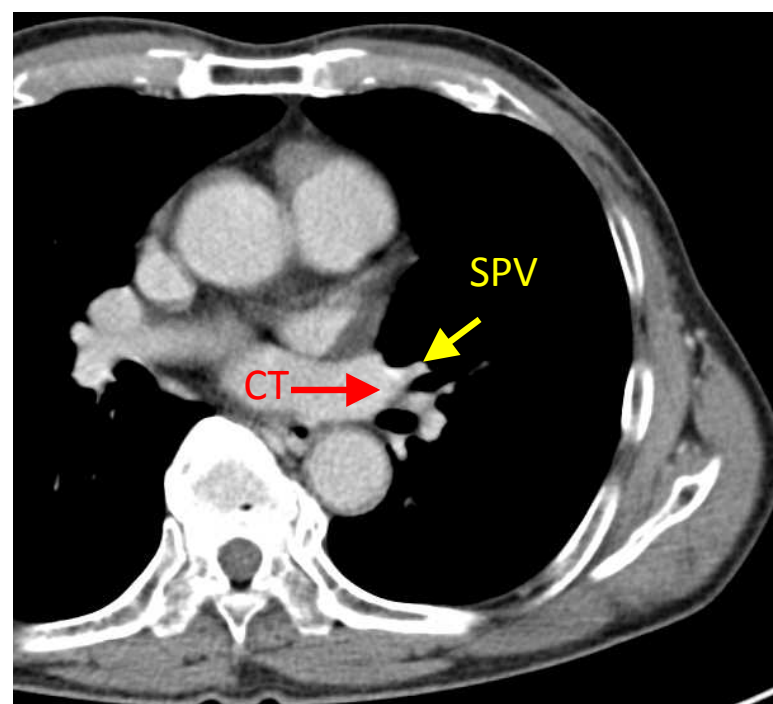

(a)

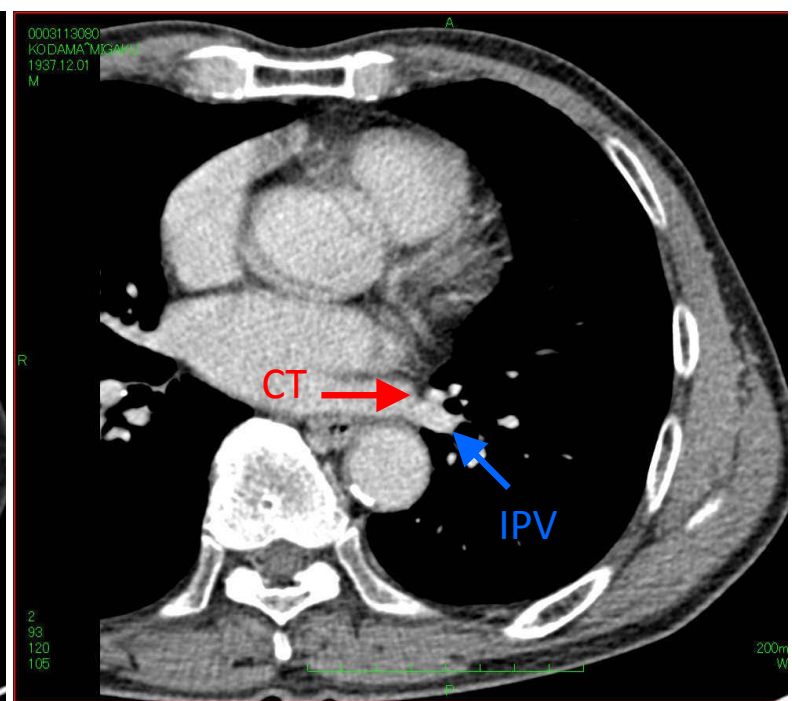

(b)

Figure 2. The superior pulmonary vein (SPV) and the inferior pulmonary vein (IPV) are not simultaneously displayed at the slice level of the common trunk (CT). (a) The slice level displayed the connection of the SPV (yellow arrow) and the common trunk (CT) (red arrow); (b) The slice level displayed the connection of the IPV (blue arrow) and the common trunk (CT) (red arrow).

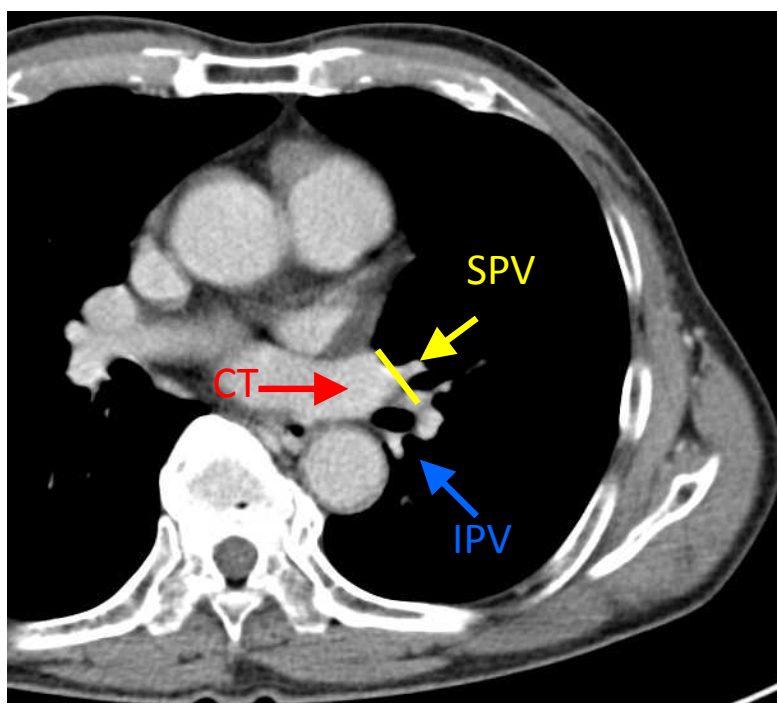

(a)

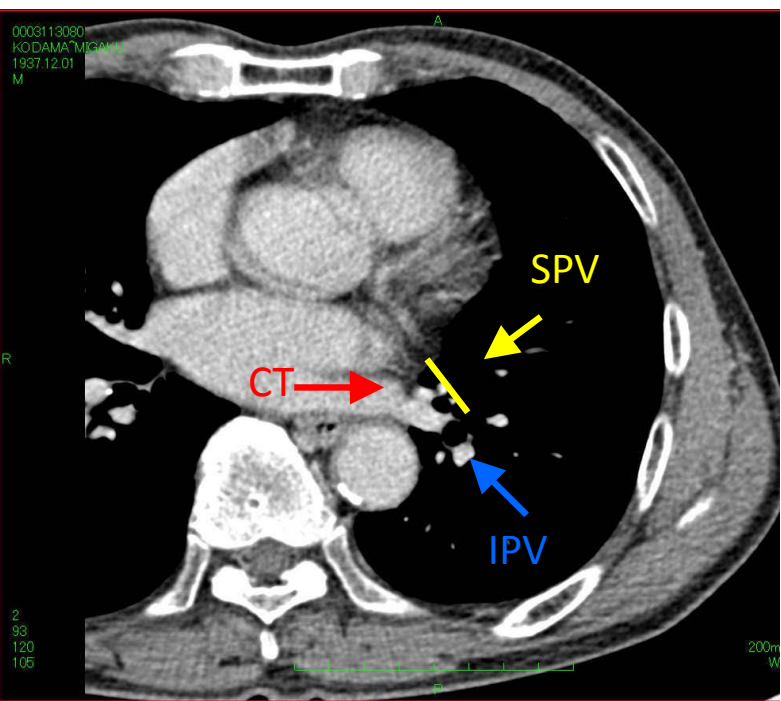

(b)

Figure 3. To perform an upper lobectomy, the SPV should be resected at the position of the yellow line ((a), (b)). (a) The slice level displayed the connection of the SPV (yellow arrow) and the common trunk (CT) (red arrow), where we should cut the SPV; (b) The slice level displayed the connection of the IPV (blue arrow) and the common trunk (CT) (red arrow), if the SPV had been cut at the peripheral site, the IPV would be preserved.

Kawakita N. et al. [1] reported 2 cases. In the left upper lobectomy for lung cancer $\left(\mathrm{S}^{4}\right)$, intraoperatively, a common trunk was confirmed. Although they resected the SPV, an unexpected cutting of the common trunk occurred. As they considered the curability of the interlobular invasion to the lower lobe, they had performed an incidental pneumonectomy. In another case of a common trunk, it was preoperatively recognized by three-dimensional computed tomographic scanning. The left upper division $\left(\mathrm{S}^{1+2}\right.$, lung cancer) was safely performed without cutting of the common trunk.

In the report of Matsumoto I. et al. [2], when they performed an upper lobectomy of lung cancer, there were extensive adhesions, incomplete lobulation and tumor infiltration of the main pulmonary artery. Intraoperatively, 


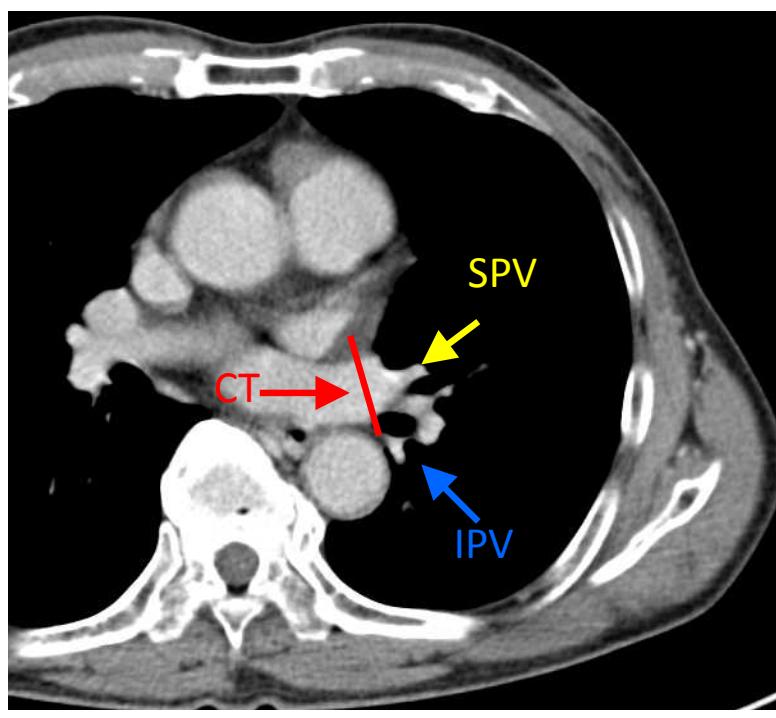

(a)

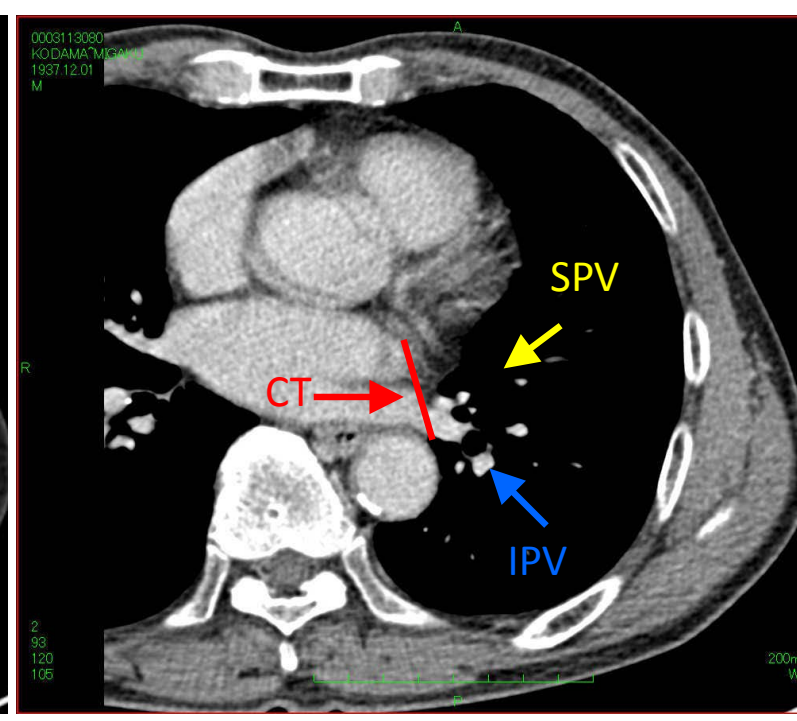

(b)

Figure 4. We intended to cut the SPV, however, we cut the common trunk without its recognition (red line), which resulted in cutting of the IPV. (a) The slice level displayed the connection of the SPV (yellow arrow) and the common trunk (CT) (red arrow). Actually, although the SPV had been cut, a common trunk was resected (red line); (b) The slice level displayed the connection of the IPV (blue arrow) and the common trunk (CT) (red arrow). Although we resected the common trunk (red line), which resulted from cutting of the IPV.

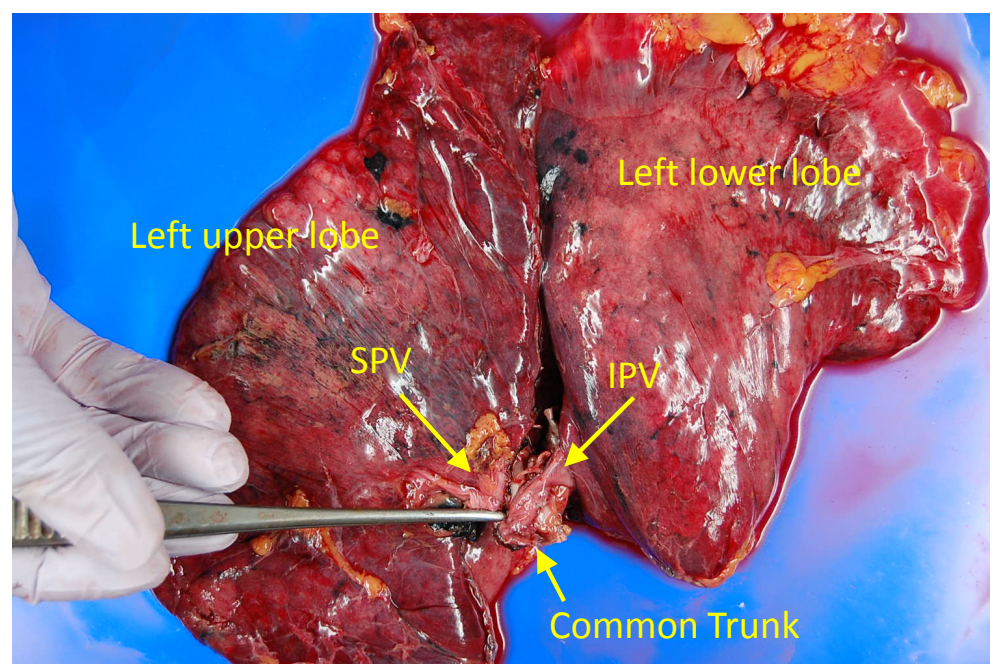

Figure 5. The specimen of the pneumonectomy of the left lung. The upper lobe, lower lobe, SPV, IPV, and common trunk are shown. The place sandwiching with forceps was where we should have cut in order to perform an upper lobectomy. The expected cut line of the SPV was buried in the upper lobular parenchyma.

they could not identify a common trunk before excising the left upper lobe. After completing the upper lobectomy and releasing of isolation ventilation, the carbon dioxide partial pressure of the expired air was extremely low and interruption of the pulmonary circulation of the lower lobe was suspected. Intraoperatively, a normal IPV was absent, as the vein formed a common trunk outside the pericardium and drained into the left atrium at the location of the normal SPV. Although the reconstruction of the lower pulmonary vein was considered, the residual pulmonary vein was not the SPV and the blood flow had already been interrupted for too long, thus there was no choice but undergo excision of the lower lobe. Retrospectively, they identified the anatomical anomalies involving the pulmonary veins by a preoperative CT film.

In the report of Meguro H. et al. [3], intraoperatively, they did not recognize an anomalous single pulmonary vein. After the left upper lobectomy of lung cancer $\left(\mathrm{S}^{3}\right.$ lesion), on the $3^{\text {rd }}$ postoperative day, congestion of the 
Table 1. Summary of common trunk of pulmonary vein in 6 reports.

\begin{tabular}{|c|c|c|c|c|c|c|c|c|}
\hline $\begin{array}{l}\text { Case } \\
\text { No. }\end{array}$ & $\begin{array}{l}\text { e Tumor } \\
\text { location }\end{array}$ & Diagnosis & $\begin{array}{c}\text { The scheduled } \\
\text { operation }\end{array}$ & $\begin{array}{l}\text { Unexpectedly } \\
\text { cutting }\end{array}$ & $\begin{array}{l}\text { At the time of } \\
\text { recognition of a } \\
\text { common trunk }\end{array}$ & Final surgery & Notes & $\begin{array}{l}\text { Reference } \\
\text { No. }\end{array}$ \\
\hline 1 & Left $S^{4}$ & $\begin{array}{l}\text { Lung } \\
\text { cancer }\end{array}$ & $\begin{array}{c}\text { Upper } \\
\text { lobectomy }\end{array}$ & + & $\begin{array}{l}\text { Intraoperatively, after } \\
\text { cutting of SPV }\end{array}$ & $\begin{array}{c}\text { Incidental } \\
\text { pneumonectomy }\end{array}$ & After cutting of SPV & [1] \\
\hline 2 & Left $S^{1+2}$ & $\begin{array}{l}\text { Lung } \\
\text { cancer }\end{array}$ & $\begin{array}{l}\text { Upper division } \\
\text { segmentectomy }\end{array}$ & - & $\begin{array}{c}\text { Preoperatively, } \\
\text { three-dimensional } \\
\text { tomographic scanning }\end{array}$ & $\begin{array}{l}\text { Upper division } \\
\text { segmentectomy }\end{array}$ & $\begin{array}{l}\text { The cutting of IPV could be } \\
\text { avoided }\end{array}$ & [1] \\
\hline 3 & Left $S^{1+2}$ & $\begin{array}{l}\text { Lung } \\
\text { cancer }\end{array}$ & $\begin{array}{l}\text { Upper } \\
\text { lobectomy }\end{array}$ & + & $\begin{array}{c}\text { Intraoperatively, after } \\
\text { lobectomy, interruption } \\
\text { of pulmonary circulation } \\
\text { of lower lobe }\end{array}$ & $\begin{array}{l}\text { Upper lobectomy, } \\
\text { excision of lower } \\
\text { lobe }\end{array}$ & $\begin{array}{l}\text { Extensive adhesions, } \\
\text { incomplete lobulation and } \\
\text { tumor infiltration of the } \\
\text { main pulmonary artery }\end{array}$ & [2] \\
\hline 4 & Left $S^{3}$ & $\begin{array}{l}\text { Lung } \\
\text { cancer }\end{array}$ & $\begin{array}{l}\text { Upper } \\
\text { lobectomy }\end{array}$ & + & $\begin{array}{c}\text { On } 3^{\text {rd }} \text { postoperative day, } \\
\text { postoperative } \\
\text { pulmonary venous } \\
\text { congestion }\end{array}$ & $\begin{array}{l}\text { Completion } \\
\text { pneumonectomy }\end{array}$ & $\begin{array}{c}\text { Preoperatively, } \\
\text { intraoperatively, no } \\
\text { confirmation of common } \\
\text { trunk }\end{array}$ & [3] \\
\hline 5 & $\begin{array}{l}\text { Left } \\
\text { upper } \\
\text { lobe }\end{array}$ & $\begin{array}{l}\text { Lung } \\
\text { cancer }\end{array}$ & $\begin{array}{l}\text { Upper } \\
\text { lobectomy }\end{array}$ & + & Intraoperatively & $\begin{array}{l}\text { Upper lobectomy, } \\
\text { reconstruction }\end{array}$ & IPV was reconstructed & [4] \\
\hline 6 & Left $B^{6}$ & $\begin{array}{l}\text { Lung } \\
\text { cancer }\end{array}$ & $\begin{array}{l}\text { Lower } \\
\text { lobectomy }\end{array}$ & - & $\begin{array}{c}\text { Intraoperatively, no } \\
\text { finding of IPV to resect } \\
\text { IPV }\end{array}$ & Lower lobectomy & IPV returned to SPV & [5] \\
\hline 7 & Left $S^{10}$ & $\begin{array}{l}\text { Lung } \\
\text { cancer }\end{array}$ & $\begin{array}{l}\text { Lower } \\
\text { lobectomy }\end{array}$ & - & $\begin{array}{l}\text { Intraoperatively, no } \\
\text { finding of IPV }\end{array}$ & Lower lobectomy & $\begin{array}{c}\text { Retrospectively, no } \\
\text { existence of usual locations } \\
\text { of SPV and IPV by } \\
\text { computed-tomographic } \\
\text { scanning }\end{array}$ & [6] \\
\hline
\end{tabular}

left lower lobe gradually increased. They suspected postoperative venous congestion as the left pulmonary vein was not visualized by a pulmonary arterial contrast radiographic examination. The cutting of the left single common trunk vein had occurred, and a redo operation of the left lower lobectomy was performed on the $6^{\text {th }}$ postoperative day. There was no existence of the IPV, thus the residual lower lobe was removed by cutting the pulmonary artery and lower bronchus, and completion of the pneumonectomy was performed, which resulted in forming a common trunk of the pulmonary vein, the situation which had not been confirmed preoperatively or intraoperatively.

In other case of Nakamura T. et al. [4], during the left upper lobectomy for lung cancer, they incidentally cut a common trunk, and the reconstruction of the SPV was later proven to be the common trunk, which was cut by an endo stapler. Since the IPV had been resected, after finishing cutting the vessels at the site of the usual upper lobectomy and upper bronchus, the cut margin of the trunk was anastomosed to the left atrium using a pericardium patch and dilating the caliber of the trunk. The IPV and the cut margin of the common trunk were successfully reconstructed and there were no further concerns.

In the case of Ohno K. et al. [5], they performed a left lower lobectomy of the left lung cancer $\left(\mathrm{B}^{6}\right)$. After they cut the $\mathrm{A}^{6}$ branches and common basal pulmonary artery, they exposed a vessel from lower lobe at the interlobular space, which returned and connected to the SPV, which formed an extrapericardial single trunk returning to the left atrium. There was no existence of the usual IPV at the location of the posterior back side. After exposure of the IPV and SPV, the lower lobectomy was performed.

In another case of Kamiyoshihara M. et al. [6], during the left lower lobectomy of lung cancer $\left(S^{10}\right)$, they found the absence of the IPV. The intralobular vessel from the upper lobe was found behind the location of the intralobular pulmonary artery, which continued to connect to the lower lobe, which was recognized as an IPV that formed an extrapericardial single trunk. The IPV was resected at the peripheral site of the common trunk in order not to influence the SPV. Retrospectively, computed-tomographic scanning showed no existence of the usual locations of the SPV and IPV, which displayed that the common trunk returned to the left atrium at the branching of the upper and lower bronchi.

We summarized the above 7 surgical cases of the common trunk of the pulmonary vein (Table 1), which were the cases of the upper lobectomy $(n=4)$, lower lobectomy $(n=2)$, and upper division segmentectomy $(n=1)$. 
For the four upper lobectomies with a common trunk, the abnormality could not be preoperatively and intraoperatively obtained before their resection. Postoperatively, two cases were confirmed as abnormal venous connections by the preoperative computed-tomographic scanning film. For the two cases of the lower lobectomies, which had not been recognized preoperatively, were found intraoperatively. These two cases could have avoided cutting the common trunk and they could perform the usual lower lobectomy. Finally, pneumonetomies were performed in two cases (2/6, 33.3\%), and the pneumonectomy postoperatively completed (1/6, 16.6\%). Two cases with a common trunk resulted in a normal lower lobectomy $(2 / 6,33.3 \%)$.

\section{Conclusion}

Although the present case was rare and the common trunk of the pulmonary vein was unexpectedly resected, we learned a basic rule in thoracic surgery. That is, at the preoperative phase, detailed assessment of the pulmonary vascular anatomical location and its three-dimensional relationship becomes a very important confirmation. At the intraoperative phase, recognition of the existence of the SPV and IPV and intraoperative check of an anomalous venous connection are essential, and confirmation steps would be needed before cutting the vessels to avoid an incidental pneumonectomy. Compared to the lower lobectomy cases, for the upper lobectomy cases, we need to take care and recognize the common trunk.

\section{References}

[1] Kawakita, N., Toba, H., Sakiyama, S., Sawada, T., Yamamoto, Y., Nakagawa, Y., Takizawa, H., Kenzaki, K., Kondo, K. and Tangoku, A. (2010) Lung Cancer in Patient with a Common Trunk of Left Pulmonary Veins; Report of Two Cases. KyobuGeka, 63, 915-918. (In Japanese)

[2] Matsumoto, I., Ohta, Y., Tsunezuka, Y., Sawa, S., Fujii, S., Saito, K., Oda, M. and Watanabe, G.A. (2005) Surgical Case of Lung Cancer in a Patient with the Left Superior and Inferior Pulmonary Veins Forming a Common Trunk. Annals of Thoracic and Cardiovascular Surgery, 11, 316-319.

[3] Meguro, H., Kohiyama, R., Abe, N., Takemoto, N. and Miyata, M. (1998) A Case of Single Left Pulmonary Vein with Deficiency of Left Inferior Pulmonary Vein. The Journal of the Japanese Association for Chest Surgery, 12, 529-534. (In Japanese) http://dx.doi.org/10.2995/jacsurg.12.529

[4] Nakamura, T., Koide, M., Nakamura, H. and Toyoda, F. (2009) The Common Trunk of the Left Pulmonary Vein Injured Incidentally during Lung Cancer Surgery. Annals of Thoracic Surgery, 87, 954-955. http://dx.doi.org/10.1016/j.athoracsur.2008.07.054

[5] Ohno, K., Yamasaki, Y., Yamasaki, H., Fukui, Y. and Kuwata, K. (2000) A Resected Case of Lung Cancer with an Extrapericardial Single Trunk Formed by the Left Pulmonary Veins. KyobuGeka, 53, 877-879. (In Japanese)

[6] Kamiyoshihara, M., Otaki, A., Nameki, T., Shimizu, K., Otani, Y. and Morishita, Y. (2004) Lung Cancer with an Extrapericardial Single Trunk as the Left Pulmonary Vein; Report of a Case. KyobuGeka, 57, 981-983. (In Japanese)

\section{Abbreviations}

SPV: Superior Pulmonary Vein

IPV: Inferior Pulmonary Vein 


\section{Submit or recommend next manuscript to SCIRP and we will provide best service for you:}

Accepting pre-submission inquiries through Email, Facebook, LinkedIn, Twitter, etc.

A wide selection of journals (inclusive of 9 subjects, more than 200 journals)

Providing 24-hour high-quality service

User-friendly online submission system

Fair and swift peer-review system

Efficient typesetting and proofreading procedure

Display of the result of downloads and visits, as well as the number of cited articles

Maximum dissemination of your research work

Submit your manuscript at: http://papersubmission.scirp.org/ 